\section{A deep look at African rifting}

\section{Paul Morgan}

THE East African rift valley provides geologists with a modern example of the processes that have split continents over the eons and led to the growth of new oceans. Reports elsewhere in this issue ${ }^{1,2}$ from two phases of the Kenya Rift International Seismic Project (KRISP 85 and 90 ) suggest from the structure of the rift far below the surface that the plastic asthenosphere below the Earth's crust plays an active part in the rifting.

Continental rifts are a fundamental tectonic feature of the continents, the sites of future or failed continental separation and the birth of new oceans. They are easily identified by their surface morphology as elongated depressions bounded by normal faults in the upper crust. The common association of rifts with volcanism, high heat flow, anomalous crust and upper-mantle structure, and seismic activity provides compelling evidence that the processes of rifting are not confined to upper crustal levels, but are linked to dynamic processes in the usually rigid outer lithosphere and the underlying weak asthenosphere. Since agreement was reached, over half a century ago, that rifts are generally dominated by extensional processes, two fundamental questions have remained concerning the mode and mechanism of continental rifting. What is the primary mode of extensional strain during continental rifting (irrotational pure strain or simple strain, with rotation $)^{3}$. And is the asthenosphere active or passive in the mechanism of continental rifting ${ }^{4,5}$ ?

Two phases of a multinational research project have provided the first relatively detailed models of lithospheric structure beneath the Kenya rift, a prime example of the rifting process, based upon seismic waves recorded from manmade explosive and natural earthquake sources. The first phase of the project, KRISP 85, demonstrated the applicability of seismic studies to this problem by providing evidence of three-dimensional complexity in this grossly two-dimensional structure ${ }^{6}$, and refining earlier studies of thinning of the lithosphere beneath the rift zone $^{7}$. The second phase, KRISP 90, was primarily designed to study variations in crustal thinning along and across the rift axis.

Verney Green et al. ${ }^{1}$, reporting on page 199, use arrival times from KRISP 85 , and from their own experiments for compressional seismic waves from distant earthquakes, to confirm and refine the earlier studies ${ }^{7,8}$ by mapping significant velocity anomalies in the lower crust and upper mantle beneath the Kenya rift. In the lower crust, their results indicate a 12 per cent velocity range, with the highest velocities beneath the rift axis, but significant variation in both the width and magnitude of this high-velocity anomaly along strike of the rift. In the uppermost mantle, the authors find a $10-12$ per cent decrease in velocity relative to the mantle in adjacent stable regions. The region of anomalous velocities is bounded by steep sides, and is traced from a depth of about $145 \mathrm{~km}$ up to $35-65 \mathrm{~km}$ directly beneath the rift.

The authors attribute the low-velocity anomaly to dome-like intrusions (diapirs) of hot asthenosphere in the lithosphere beneath the rift. Approximately half the anomaly is attributed to temperature contrasts between the lithosphere and asthenosphere, and half is thought to result from 3-6 per cent partial melting in the rising diapir generated by pressure-release melting. High velocities in the lower crust result from modification of the lower crust by magmas rising from the asthenosphere diapir. Variations in the widths and magnitudes of the anomalies along the rift perhaps indicate multiple diapirs along the rift axis.

Preliminary results ${ }^{2}$ from KRISP 90 reported on page 223 indicate further three-dimensional lithospheric structure associated with the Kenya rift. Using refracted and wide-angle reflected arrivals from explosive sources, the results indicate a thinning of the crust from 35 $\mathrm{km}$ in the south to $20 \mathrm{~km}$ in the north along the rift axis, and abrupt thickening of the crust by $6-10 \mathrm{~km}$ across the rift at the rift margins. A significant decrease in compressional wave velocities in the uppermost mantle, from $8.0-8.1 \mathrm{~km} \mathrm{~s}^{-1}$ beneath the rift flanks to $7.5-7.7 \mathrm{~km} \mathrm{~s}^{-1}$ beneath the rift axis, confirm other indications of anomalous upper mantle immediately beneath the rift axis ${ }^{6-8}$. In addition, the results indicate crustal thickening immediately west of the rift. This thickening is close to a major prerifting crustal boundary between the Archaean craton to the west, where the crust has been stable for 2.5 billion $\left(10^{9}\right)$ years, and the Pan-African orogenic belt which experienced major deformation about 550 million years ago.

\title{
Water goes with the flow
}

If hydrogen bonding is strong enough to cause the collapse of polymer gels and to bind acetic acid molecules into dimers in the gas phase, why does it not hold liquid water rigid? The example par excellence of a hydrogen-bonded system, water, consists of a continuous random network of tetrahedrally coordinated molecules not unlike that in vitreous silica, with bond energies much larger than the thermal energy at room temperature; yet it remains a liquid. On page 218, F. Sciortino et al. show that the fluidity of water can be ascribed to defects in the hydrogen-bonded network in which some molecules are coordinated to five neighbours, not the usual four.

To acquire the extra neighbour, one of the hydrogen bonds formed by the central molecule must be bifurcated, in that either one of its hydrogen atoms bonds to two oxygens or three of the neighbours' hydrogens are coordinated to its oxygen atom. The simulations of Sciortino et al. reveal the somewhat counterintuitive result that the higher density in the first coordination shell of five-coordinate molecules leads to increased molecular mobility. This is not, as might be thought, a consequence of weaker bonding, but of a 'flattening' of the potential-energy barriers to rotation and translation. By lowering activation energies, the local defect induced by the fifth neighbour is therefore acting as a catalyst.
Philip Ball 